\title{
Methodological Poverty and Disciplinary Underdevelopment in IR
}

\author{
Ersel Aydinlı \\ Bilkent University
}

\begin{abstract}
This article begins with the premise that the International Relations (IR) disciplinary community in Turkey has a problem: namely, it has failed to appreciate the importance of methodology. Rather, efforts to develop the local discipline and, subsequently, training within IR departments, have both emphasized 'theory', arguing that it constitutes the best route of elevating local disciplinary scholarship and enabling true dialogue with the core discipline. This article argues that, unfortunately, this focus has at best succeeded in encouraging the importation and assimilation of outside theories, and at worst, has helped to create a shell of a local discipline - ever increasing in size, but not in substance. It goes on to argue that only through development of students' and scholars' methodological competence can Turkish IR gain greater value in the global IR scholarly community, because methodology, its tools and approaches and the expertise needed to apply them in a competent and skilled manner, constitutes the universal common language of an academic discipline, and thus allows for genuine discussions and debates within a disciplinary community.
\end{abstract}

Keywords: Methodology, International Relations discipline, core, periphery

\section{Introduction}

James Rosenau once referred to theory being "imagination", and method being "art". This special issue draws on that characterization to argue that without mastering the art of methodology, imagination remains confined to the mind. The works included in this issue are therefore devoted to the development of high quality research in International Relations, based on the principle that to achieve that best quality, we have to develop students' and scholars' methodological competence. Unfortunately, recent decades in Turkish International Relations training have seen an excessive emphasis on theory, while ignoring the 'art' of methodology. At best this focus has succeeded in encouraging the importation and assimilation of outside theories, ${ }^{1}$ and at worst, it has helped in creating a shell of a local discipline — ever increasing in size, but not in substance. How would a greater focus on methodology have helped? I would argue that methodology, its tools and approaches and the expertise needed

Ersel Aydınlı, Professor, Department of International Relations, Bilkent University. Email: ersel@bilkent.edu.tr. (D) https:// orcid.org/0000-0002-8534-1159

1 See for example Ersel Aydinli and Julie Mathews, "Are the Core and Periphery Irreconcilable? The Curious World of Publishing in Contemporary International Relations." International Studies Perspectives 1, no. 3 (2002): 289-303; Ching-Chang Chen, "The Absence of Non-Western IR Theory in Asia Reconsidered," International Relations of the Asia-Pacific 11, no. 1 (2011): 1-23; Peter M. Kristensen, "How Can Emerging Powers Speak? On Theorists, Native Informants and Quasi-Officials in International Relations Discourse," Third World Quarterly 36, no. 4 (2015): 637-53; Yaqing Qin, "Development of International Relations Theory in China: Progress Through Debates," International Relations of the Asia-Pacific 11, no. 2 (2011): 231-57. 
to apply them in a competent and skilled manner, constitutes the universal language of an academic discipline. While there are certainly different methodological approaches and tools, and there may be strong disagreements about which ones are better for various purposes, they nevertheless all provide a structured way of communicating ideas that otherwise can be dismissed as just opinions. Methodological approaches and tools therefore constitute a common language, one that allows for genuine discussions and debates within a disciplinary community and thus the accumulation of scholarship. Furthermore, the common language of methodology provides a means to scholars in the disciplinary periphery to speak with their colleagues in the core. In other words, through competent and effective application of established methods of research, scholars whose voices might otherwise be easier to ignore, are more likely to be understood and therefore heard.

One of the most disturbing problems I have observed over years of teaching and researching IR in Turkey, and the problem on which I lay the blame for much of the local disciplinary community's failure to grow substantively, is both a broad lack of appreciation for the importance of methodology as well as an overall inadequacy in knowledge of and competence in applying methodological approaches and tools. Unfortunately, methodology remains undervalued in most IR departments in Turkey. We see evidence of this in the students that emerge from these departments. It has become a sadly regular occurrence in graduate student thesis and dissertation juries to be presented with explicit research questions, a review of the literature, and an explicit methodology description, but when it comes to the analysis, no true application of the stated methodology. It is obvious there are problems in the methodology training we give to our IR students. At the most basic level, there is simply not enough training being given. A look at the curricula of 38 International Relations departments across Turkey shows that the vast majority, 30, offer just one or two methods related undergraduate courses. While four departments do offer three or more such courses, another four departments offer no methods courses at all! The numbers are roughly the same at the graduate level, with six schools offering no specific graduate level methods courses, and 29 offering just one or two.

Even when training is given however, it is rare to see it done in anything more than a mechanical manner-presenting the basics but making little effort to have students engage with them in depth. It has been my experience that presentation alone is ineffective in getting students to learn anything, let alone truly digesting a range of different methodological approaches and mastering various methods. I believe however, that if a student is exposed to the personal experiences of someone who uses a particular methodology, the engagement and subsequent learning potential is much deeper. This is the starting idea behind the works in this issue. I believe that if students hear how an individual scholar came to know about and use a certain methodology, if they read narratives of scholars' personal experiences with learning about and subsequently practicing the art of a particular methodology, they will not only better understand how and when to use them, they will not be afraid to do so.

With this in mind, this special issue is intended primarily for graduate students and young scholars in the field of International Relations who are searching for guidance in expanding their methodological research skills and repertoire. Its readers have probably taken a methodology class or two at university, and they have likely received advice about particular methods or approaches from a professor or a thesis supervisor, but they may still be wondering about the options open to them, and they may be unsure about how to choose 
among them. The following articles may also be of interest to more experienced scholars who are curious not only about different methodologies used in IR, but also about the types of experiences their colleagues have had in learning about and using those methodologies.

This issue does not offer in-depth, step-by-step instructions on how to use the methodologies and methods discussed, nor does it in any way claim to be an all-inclusive exploration of methodologies in IR. Rather, it offers a look into 10 different methods and methodologies used for conducting research in IR, from the behind-the-scenes perspectives of scholars who have actually used them in their own work. In their articles, the authors in this issue provide background information on the method or methodology in question, including its history, primary questions it has been used to answer, and any major research programs and projects associated with it. They then share frank and honest insights into their own personal histories with the methods and methodologies: how did they decide to use them, what alternatives did they consider, what kinds of training did they receive and what kinds of obstacles did they face during that training? Finally, the authors explore their application of the method or methodology with respect to their current or past research, and why they found it the most appropriate for the research question(s) being asked.

\section{How Do We Do Research?}

Research begins with genuine and well-informed questions. We may sometimes tell our students that there are no 'bad' questions when we're trying to encourage classroom interaction, but in research, there may very well be 'bad' questions. The first kind of 'bad' question is one that is disingenuous. In other words, research questions should be real ones for which you are genuinely seeking answers. If you already know the answer (or believe that you do), then you are not involved in research, you are simply trying to prove a point. Questions also need to be legitimate. To draw an analogy, while inspiration may seem to come out of the blue, in fact it's generally based on past experiences, observations, and so on. Likewise, a 'legitimate' research question should be based on something. It may emerge from past experiences or it may build on past research or seek to extend existing theory, that is, it may draw on a practical or a theoretical background, but it should extend logically from something. A research question that seems to come 'out of the blue' will likely address neither a practical issue nor a conceptual one, and is therefore probably not going to contribute to knowledge building. Thirdly, the question should be 'answerable'. There is little point in asking questions that are impossible to answer, whether it be because they are worded in an overly general manner (e.g. how do social media impact voting practices?) or for practical reasons (e.g. a question requiring the collection of qualitative data over decades). To be 'answerable' therefore, questions need to be clear, precise, and feasible. Fourthly, 'good' questions should be important, in the sense that they will be of interest to others. The answers to the questions may have practical implications or not, they may contribute to conceptualizations or theory building, but they must at some level be of interest to a clearly identified audience. This is not to imply that the audience must be large, but it must be evident who the audience is.

Once ready with genuine, legitimate, answerable, and important research questions, researchers must then determine the best methodology for seeking answers to them. Perhaps the most fundamental point in selecting a methodology is that it be appropriate for answering the questions in hand, not the other way around. You should not, therefore, be adhering to a 
methodology like an ideology, and trying to use it to answer everything. Methods are tools that we can develop skills in using, and the more tools you are able to master, the bigger your toolkit will be to address questions. With this larger capacity you will not only be able to answer more, diverse research questions effectively, but you will also be able to address the same research questions in alternative ways, thereby broadening your capacity to find answers to them. To draw on the old saying, 'if a man has a hammer everything starts looking like a nail', we might say that researchers with a limited set of methods in their repertoire will have an equally limited perspective on research. This issue is therefore both a starting point to understanding the kinds of methodological options that exist, and an acknowledgement of the vital importance that methodology plays in guiding the direction and value of our scholarship.

\section{How should This Special Issue be used?}

As stated at the beginning of this introduction, this issue is intended primarily as a methodology guide for young scholars in the field of International Relations. First, it may serve as an accompanying textbook for classes on methodology in International Relations. In this case, it will be most effective in a complementary role to a more detailed training manual on various methods, offering the personal insights and experiences that show how scholars come to use certain methods and approaches. Secondly, it may provide suggestions to any researcher in the field who would like to explore alternative methodological tools and approaches or would just like to compare his or her own methodological experiences with others'. In either case, the issue aims to help everyone involved in International Relations research to expand their methodological horizons.

\section{Articles}

The following articles offer insights into ten different methods/methodologies used in International Relations research. While by no means exclusive, the issue strives to present a diverse selection of methods and methodologies, deriving from various practical and epistemological approaches to research. As noted above, it aims to give a broad - though by no means exclusive- - look not just at some methods/methodologies that can be used, but at how practicing scholars actually use them, and why.

The articles can be roughly divided as follows: four articles dealing with broadly quantitative methods of research, two embracing either explicitly mixed methods or a 'beyond quantitative/qualitative' approach, and four articles dealing with broadly qualitative methods of research. The remaining two-Aktürk's opening and Travlos's closing articlesadopt a slightly different take on the methodology question by addressing broader issues of research design rather than focusing on a particular methodology.

In his article, Aktürk provides a broad picture of Turkish foreign policy scholarship by looking at the research designs used in studies published over the last two decades and classifying them according to the temporal dimension of the causality relationship between their dependent and independent variables - or lack thereof. Basically, do the investigated cause(s) and outcome(s) unfold over long or short periods of time? He applies a model that draws analogies with natural disasters to clarify the temporal concept, for example, 'tornado' is used to describe events that are quick to develop and quick to end, while 'earthquakes' represent those that take a long time to develop but then the actual event is over very quickly. 
Using the model, Aktürk explores political research conducted in Turkey. He finds that a large number of studies do not have clear independent variables, and despite claims to causalitygenerally of the 'global warming' type - they would more accurately be categorized as 'noncausal description' works. He ends by providing guidelines for overall research design in order to address this problem.

Belgin Şan-Akca's article leads off the issue's exploration of various quantitative methods in IR research by looking at the use of large-N datasets. She first provides a critical overview of work done on transnational dimensions of internal conflict and then gives an account of her personal experience in conducting research on how states and nonstate armed groups interact. In this spirit, her piece includes insights into both broad research issues, such as gaps in the existing research on internal conflicts, and specifics of her own decade-long experience of designing and building up the Dangerous Companions Project, including details on data collection and coding. She concludes with clear suggestions for future research in conflict studies and IR academic scholarship in Turkey.

Akın Ünver's article first provides an excellent historical overview of Computational Social Sciences before delving into its specific application in International Relations researchComputational International Relations, or ComInt. As a guide to newcomers to ComSoc and ComInt, Ünver lays out five main approaches to mapping digital data: a) language/text, b) mapping, c) modelling, d) communication, and e) networks. By drawing closely on his own experiences, he provides insights into two critical aspects of training in ComInt, namely the technical foundation that students need in order to conduct such research, and, what he deems the even more challenging one, understanding the actual degree of technical skills that are necessary to learn. He then goes on to explore the specific application of ComInt to research on social media's relationship with political processes and describes exactly how computational tools helped him develop his own scholarship in this area. Interestingly, despite an instinctive tendency to place computational methods firmly into the quantitative camp, Ünver argues that they are in fact appropriate for bridging the gap between qualitative and quantitative approaches and serving as the basis for true multi-method research design.

Continuing with computer-based methodologies, the article by Emre Hatipoğlu et al. looks specifically at the analysis of social media data in international relations research. After providing a background to automated text analysis in IR including past literature of its use and its primary terminology and techniques, the authors discuss how using data from Twitter in particular compares with analysis of more traditional international relations texts. In doing so, they also share their own experiences with learning about and becoming proficient in automated text analysis techniques and provide information on the types of training that an IR scholar needs in order to apply such methods. To illustrate the methodology further they provide detailed information on the development of one particular technique of conducting textual analysis on Twitter, the Longest Common Subsequence Similarity Metric (LCSSM), which automatically clusters tweets with content. Finally, they show how they have actually used the LCSSM technique to help analyze public opinion in Turkey towards Syrian refugees.

Fifth article delves deeply into quantitative analysis, with Özgür Özdamar's presentation of the use of expected utility modeling and game theory in International Relations research. In line with the structure of all works in this special issue, Özdamar's piece begins with a thorough look at the history of expected utility theory, which was developed to explain decision-making processes under uncertain conditions. He goes on to explain in detail the 
model's theoretical foundations, how the model actually works, and the kind of data needed to use it. Following a narrative of his personal experience with learning about and using expected utility modelling, the author brings the abstract to life by giving a step-by-step account of how he applied such modeling and game theory approaches in his forecasting of future developments in international bargaining on the Iranian nuclear program.

Ali Fisunoğlu's article on system dynamics modeling on the surface involves another highly quantitative method of conducting research in political science or international relations, but the author highlights that in fact this approach can be seen as an alternative to the traditional dichotomous view of qualitative/quantitative research methods. Fisunoğlu shows how this is the case by first offering a history of system dynamics models and then describing how they have been used in the social sciences alongside a critical comparison of the approach with more traditional qualitative and quantitative methods. Drawing throughout on a frank discussion of his own experience, he goes on to inform the reader about the basic idea behind system dynamics models and carefully shows how they have been used specifically in studies related to arms races and the spread of interstate conflicts.

With İsmail Erkam Sula's article we reach a kind of mid-point in the collection, as the author consciously highlights a multi-method approach combining qualitative content based coding analysis with quantitative event data analysis. He walks the reader through the steps taken in developing what he designates as an 'eclectic coding scheme' using a Role theory framework, and then shows how it was applied to build up the Turkish Foreign Policy Roles and Events Dataset (TFPRED). To set the stage for this discussion, Sula first briefly reviews the literature both on how role theory frameworks have been applied and on the use of event data in foreign policy analysis. Following an explanation of his experience with designing and creating the TFPRED and showing the kinds of empirical results that can be achieved by using this methodological approach, he concludes with a critical assessment of its limitations.

In eight article, authors Senem Aydın-Düzgit and Bahar Rumelili delve into a method that may be one of the most commonly named approaches to research in International Relations, but also, arguably, one of the most frequently misunderstood: Discourse Analysis. In their piece the two authors present a clear and very thorough overview of the conceptual and epistemological foundations of the approach, before moving on to an honest narrative of their personal histories with applying it. Finally, in their effort to demystify what Discourse Analysis is and how exactly it can be used, they provide a hands-on example of actual discursive analysis of a British newspaper article from the 1960s discussing the extent to which Turkey is - or is not - a part of Europe. Their article wraps up with a frank discussion of the challenges scholars may face in conducting discourse analyses and how best to overcome them.

Ninth article shines a light on the sometimes fraught disciplinary border between the fields of international relations and history, with Mustafa Serdar Palabiylk's look at the use of comparative historical analysis (CHA) in international relations research. The article begins with a detailed description of the main premises of CHA and how it evolved, and then provides a practical categorization of CHA approaches based on their varying modes and aims. In his comparison, Palabiylk guides the reader through the advantages and disadvantages of each form in order both to show how each might best contribute to research as well as to caution against practical difficulties that researchers might face in applying them. The article concludes with the author's in-depth discussion of his own experiences with using CHA, and 
in doing so, he makes a powerful case for the importance of history-based research methods in IR scholarship.

Also treading the line between history and international relations is Egemen Bezci's work in tenth article, in which he focuses on a rigorous approach to archival research. Following his discussion of a broad 'international history' approach to historical studies of Turkish Foreign Policy, Bezci uses his own work on intelligence affairs to particularly highlight the challenges and risks of these types of methods, and archival research in particular. Drawing on his experiences he outlines not only the different types of archives he used, but gives strategies and tips for improving efforts at objectivity and accuracy, while recognizing the inherent flaws and obstacles that exist when relying on archived materials.

The last of the focused articles on specific methodologies is Alper Kaliber's look at another very commonly used method of research, semi-structured interviewing. In particular he discusses the idea of a reflectivist approach to this qualitative form of interviewing, one that argues that while this research tool should be recognized as having inherent political consequences, that does not mean it should be dismissed entirely. The approach instead proposes that the researcher assume a self-critical approach that consciously acknowledges his/her role and influence on the interview and interviewee. Kaliber's article first sets the stage by describing his own personal experience with learning about and using interviewing in his own research. He then provides a thorough background to the debates surrounding the use of interviewing as a data collection method. The remainder of the article gives the reader a clear description of precisely how, why, and in what ways researchers may use this tool, divided according to three stages of pre, during, and post-interview. Throughout, he addresses a variety of important issues, from practical details of interviewing to broader issues such as ethics and consent taking.

Konstantinos Travlos' closing article to the issue takes on the form of a dialogue, with the author guiding the reader through the theoretical and methodological decision-making processes that led to the final product. The reader sees both the full research text, exploring the issue of 'public' military mobilization on the part of weak actors during a dispute as a way of triggering third party intervention and subsequent accommodation by the stronger actor, as well as the author's running commentary about his thinking and how it guided his decisions about the final content of the paper. Travlos's detailed, thoughtful, and highly practical comments provide insights into all aspects of the research design process, from conception of the idea, through writing up the results, and reflect the author's own journey as a researcher.

\section{Bibliography}

Aydinli, Ersel, and Julie Mathews. "Are the Core and Periphery Irreconcilable? The Curious World of Publishing in Contemporary International Relations.” International Studies Perspectives 1, no. 3 (2002): 289-303.

Chen, Ching-Chang. "The Absence of Non-Western IR Theory in Asia Reconsidered." International Relations of the Asia-Pacific 11, no. 1 (2011): 1-23.

Kristensen, Peter M. "How Can Emerging Powers Speak? On Theorists, Native Informants and Quasi-Officials in International Relations Discourse.” Third World Quarterly 36, no. 4 (2015): 637-53.

Qin, Yaqing. "Development of International Relations Theory in China: Progress Through Debates.” International Relations of the Asia-Pacific 11, no. 2 (2011): 231-57. 
